\title{
Ultrafine Structure and High Strength in Cold-Rolled Martensite
}

\author{
Huang, Xiaoxu; Morito, S.; Hansen, Niels; Maki, T.
}

Published in:

Metallurgical and Materials Transactions A: Physical Metallurgy and Materials Science

Link to article, DOI:

$10.1007 / \mathrm{s} 11661-012-1275-5$

Publication date:

2012

Document Version

Publisher's PDF, also known as Version of record

Link back to DTU Orbit

Citation (APA):

Huang, X., Morito, S., Hansen, N., \& Maki, T. (2012). Ultrafine Structure and High Strength in Cold-Rolled Martensite. Metallurgical and Materials Transactions A: Physical Metallurgy and Materials Science, 43A(10), 3517-3531. https://doi.org/10.1007/s11661-012-1275-5

\section{General rights}

Copyright and moral rights for the publications made accessible in the public portal are retained by the authors and/or other copyright owners and it is a condition of accessing publications that users recognise and abide by the legal requirements associated with these rights.

- Users may download and print one copy of any publication from the public portal for the purpose of private study or research.

- You may not further distribute the material or use it for any profit-making activity or commercial gain

- You may freely distribute the URL identifying the publication in the public portal 


\title{
Ultrafine Structure and High Strength in Cold-Rolled Martensite
}

\author{
X. HUANG, S. MORITO, N. HANSEN, and T. MAKI
}

\begin{abstract}
Structural refinement by cold rolling (10 to 80 pct reductions) of interstitial free (IF) steel containing $\mathrm{Mn}$ and $\mathrm{B}$ has been investigated from samples with different initial structures: (a) lath martensite, (b) coarse ferrite (grain size $150 \mu \mathrm{m}$ ), and (c) fine ferrite $(22 \mu \mathrm{m})$. Unalloyed IF steel with a coarse grain size $(120 \mu \mathrm{m})$ has also included based on a previous study. Deformation microstructures and structural parameters have been analyzed by transmission electron microscopy and electron backscatter diffraction, and mechanical properties have been characterized by hardness and tensile testing. At low to medium strains, lath martensite transforms into a cell block structure composed of cell block boundaries and cell boundaries with only a negligible change in strength. At medium to large strains, cell block structures in all samples refine with increasing strain and the hardening rate is constant (stage IV). A strong effect of the initial structure is observed on both the structural refinement and the strength increase. This effect is largest in lath martensite and smallest in unalloyed ferrite. No saturation in structural refinement and strength is observed. The discussion covers the transformation of lath martensite into a cell block structure at low to medium strains where the driving force is suggested to be a decrease in the dislocation line energy. Medium to large strain-hardening mechanisms are discussed together with structure-strength relationships assuming additive stress contributions from dislocations, boundaries, and elements in solid solution. Good agreement is found between flow stress predictions and stress values observed experimentally both in the initial undeformed martensite and in deformed samples.
\end{abstract}

DOI: $10.1007 / \mathrm{s} 11661-012-1275-5$

(C) The Minerals, Metals \& Materials Society and ASM International 2012

\section{INTRODUCTION}

STRUCTURAL refinement by plastic deformation to high strain has been explored extensively in metallic materials because of the close relationship between a fine structural scale and high strength. The structural refinement has its cause in the formation and multiplication of dislocations that interact and are stored in the form of low-angle dislocation boundaries and high-angle boundaries, which together subdivide the structure on a finer and finer scale as the strain is increased. ${ }^{[1]}$ An enhancement of the structural refinement may therefore be achieved if the initial structure can be tailored in a way that it can enhance the dislocation density at a given strain. Three such ways are explored in the present study, as follows:

- To introduce a high dislocation density in the initial structure through a martensitic transformation

- To increase the dislocation density by reducing the grain size of the initial structure

- To increase the dislocation density by introducing elements in solid solution

X. HUANG and N. HANSEN, Senior Scientists, are with the Department of Wind Energy, Danish-Chinese Center for Nanometals, Technical University of Denmark, Risø Campus, DK-4000 Roskilde, Denmark. Contact e-mail: xihu@risoe.dtu.dk S. MORITO, Associate Professor, is with the Department of Materials Science, Shimane University, Matsue 690-8504, Japan. T. MAKI, Executive Advisor, is with the Nippon Steel Corporation, Futtsu, Chiba 293-8511, Japan.

Manuscript submitted February 3, 2012.

Article published online July 10, 2012
The effect of a martensitic transformation has been demonstrated ${ }^{[2,3]}$ by cold rolling of low-carbon steels to a reduction of $50 \mathrm{pct}$, which leads to an ultrafine deformation structure. In parallel, a fine deformation structure has been produced by cold rolling of unalloyed ultralow carbon ( 0.002 mass pet) lath martensite to a thickness reduction of 80 pct. $^{4,5]}$ In the latter study, it was also observed that the martensitic structure by rolling is transformed into a typical cell-block structure that characterizes deformed face-centered cubic (fcc) and body-centered cubic (bcc) metals of medium to high stacking fault energy. ${ }^{[1]}$

A reduction in the grain size of initial structure is expected to increase the dislocation density at a given strain. ${ }^{[6-8]}$ The effect is present at low and medium strains due to an increase in the dislocation density in the form of statistically stored and geometrically necessary dislocations. ${ }^{[9]}$ At large strain an effect of grain size can also be found. For example, it has been observed in pure nickel, cold-rolled to strain of $\varepsilon_{\mathrm{vM}}=4.5$ that the dislocation density increases and the boundary spacing decreases when the grain size is reduced from $500 \mu \mathrm{m}^{[10]}$ to $70 \mu \mathrm{m} .{ }^{[11]}$ As to the effect of elements in solid solution, it is well established that their presence leads to structural refinement related to a reduction in dynamic recovery thereby increasing the dislocation density at a given strain.

The present study follows the previous findings in order to carry out a systematic investigation of the effect of four initial structures in ultralow carbon interstitial free (IF) steels; the first three structures are present in an 
IF steel with addition of $\mathrm{B}$ and $\mathrm{Mn}$, and the last structure is present in an unalloyed IF steel:

- Lath martensite (LM)

- Coarse ferrite (CF) with a grain size of $150 \mu \mathrm{m}$

- Fine ferrite (FF) with a grain size of $20 \mu \mathrm{m}$

- Unalloyed coarse ferrite (UCF) with a grain size of $120 \mu \mathrm{m}^{[12]}$

The samples have been cold rolled up to a reduction of 80 pct, and the structural evolution has been characterized by transmission electron microscopy (TEM) and electron backscatter diffraction (EBSD). The texture has been characterized by X-ray diffraction and the mechanical properties by hardness and tensile testing. The experimental findings are analyzed in order to address the following questions:

- To what extent can the structure be refined and the strength be increased by plastic deformation and will saturation be observed at large strain?

- What is the driving pressure for the structural transition at low and medium strain from lath martensite to a cell-block structure?

- What causes the deformation resistance and what are the strengthening parameters both in the initial and in the deformed state and can a realistic flow stress be predicted based on these parameters?

- Is the precursor structure an important parameter when processing nanostructured metals with high strength by plastic deformation?

These questions are the basis for the analysis and discussion of experimental observations focusing on the microstructural evolution, strengthening mechanisms, and parameters and prediction of strength structure relationships.

\section{EXPERIMENTAL PROCEDURES}

An Fe-0.0026C-1.48Mn-0.046Ti-0.015Al-0.0026B (mass pct) steel was used. Mn and B were added to improve hardenability, and the addition of $\mathrm{Ti}$ was to scavenge $\mathrm{C}$ and $\mathrm{N}$ in solution. A steel sample with the same composition was examined in a previous study. ${ }^{[4,5]}$ After austenitizing at $1473 \mathrm{~K}\left(1200^{\circ} \mathrm{C}\right)$ for $0.6 \mathrm{ks}$, specimens were quenched into iced brine to obtain a LM structure or furnace cooled to obtain CF with a grain size of $150 \mu \mathrm{m}$. In addition to $\mathrm{LM}$ and $\mathrm{CF}$ samples, a sample with a fine grain size of $12 \mu \mathrm{m}$ (FF) was prepared by recrystallizing cold-rolled (50 pct) ferrite at $573 \mathrm{~K}\left(300{ }^{\circ} \mathrm{C}\right)$ for $1.8 \mathrm{ks}$. Microstructures of undeformed and cold-rolled specimens were characterized by optical microscopy, scanning electron microscopy (SEM) equipped with EBSD facility, and TEM. For the EBSD analysis, a system of TexSEM laboratories (Provo, UT) installed in a Hitachi S3100 SEM (Hitachi, Tokyo, Japan) or in a JEOL JSM-6500F SEM (JEOL Ltd., Tokyo, Japan) was used. For the orientation and misorientation analyses in the TEM, semiautomatic orientation determination methods based on
Kikuchi diffraction installed in a Philips CM200 TEM (Philips, Amsterdam, the Netherlands) and a JEOL JEM-2000FX TEM were used. ${ }^{[1,14]}$ Dislocation densities were measured on TEM micrographs by a line intercept method with convergent beam electron diffraction analysis being used to measure the local thickness of the thin-foil specimen. ${ }^{[15]}$ The mechanical properties were measured by Vickers hardness and tensile tests. The gauge dimensions of tensile test specimens were $8.5 \mathrm{~mm}$ in length, $2.0 \mathrm{~mm}$ in width, and $0.5 \mathrm{~mm}$ in thickness. Tensile tests were conducted using an initial strain rate of $2.0 \times 10^{-3} \mathrm{~s}^{-1}$, which is a strain rate within the strain rate range commonly used for tensile test at room temperature. Microstructural observations were mainly made in the section perpendicular to the transverse direction (TD) of the specimen, i.e., the ND-RD plane where ND and RD are the normal and rolling directions, respectively.

\section{RESULTS}

\section{A. Undeformed State}

The structure of LM is shown in Figure 1. This characteristic structure has been described in detail in previous papers, ${ }^{[16,17]}$ and only features of relevance to the current study will be recapitulated. Figure 1 shows that the martensitic structure is subdivided on five length scales, i.e., prior austenite grains, packets, blocks, subblocks, and laths. Based on a K-S ${ }^{[18,19]}$ orientation relationship, six variants that have a common (111) $\gamma / /$ $(110)_{\alpha^{\prime}}$ relationship have been identified within a packet. A further subdivision is into sub-blocks and laths. This subdivision is typical for martensite with a carbon content less than 0.2 mass pet and the structural parameters determined for the current samples are given in Table I. The packet and block boundaries are high-angle boundaries ( $>15 \mathrm{deg}),{ }^{[16,17]}$ whereas sub-block and lath boundaries are rotation dislocation boundaries with average misorientation angles of $7.1 \mathrm{deg}$ and $1.8 \mathrm{deg}$, respectively (Table I). The lath boundaries confine narrow volumes with a high dislocation density $6 \times 10^{14} \mathrm{~m}^{-2},{ }^{[15]}$ and the lath boundaries themselves are defined as rotation dislocation boundaries between laths belonging to the same variant. Based on TEM analyses of the lath structure, it is characterized by alternating misorientation across lath boundaries which are mixed tilt and twist boundaries. Typically, no long-range accumulative misorientations are observed. ${ }^{[17]}$ The structure of CF and FF represents typically recrystallized polycrystalline structures containing no precipitates and a very low density of dislocations.

\section{B. Deformed State}

The microstructure in LM after 10 pet rolling reduction is illustrated in Figure 2, which shows that lath boundaries have started to vanish and that this effect is most pronounced in areas near high-angle boundaries such as block boundaries. Distributions of the misorientation angles across the lath boundaries and subblock boundaries for as-quenched martensite and for 


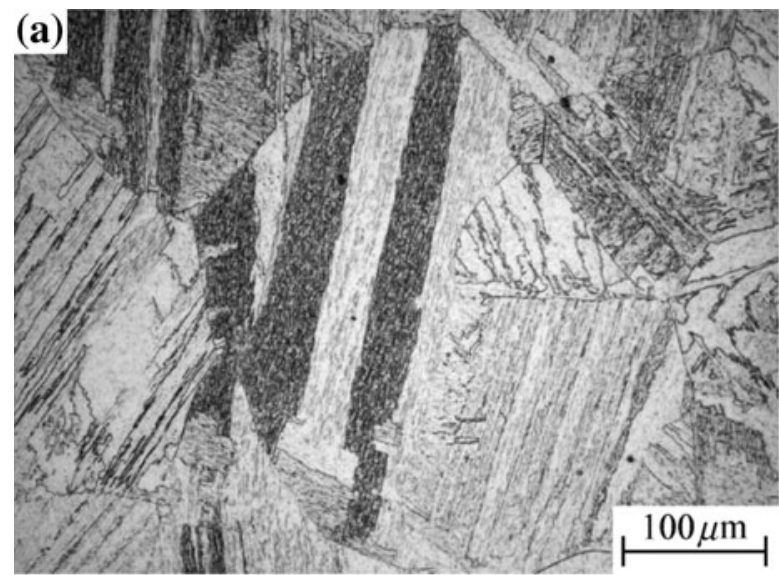

(b)
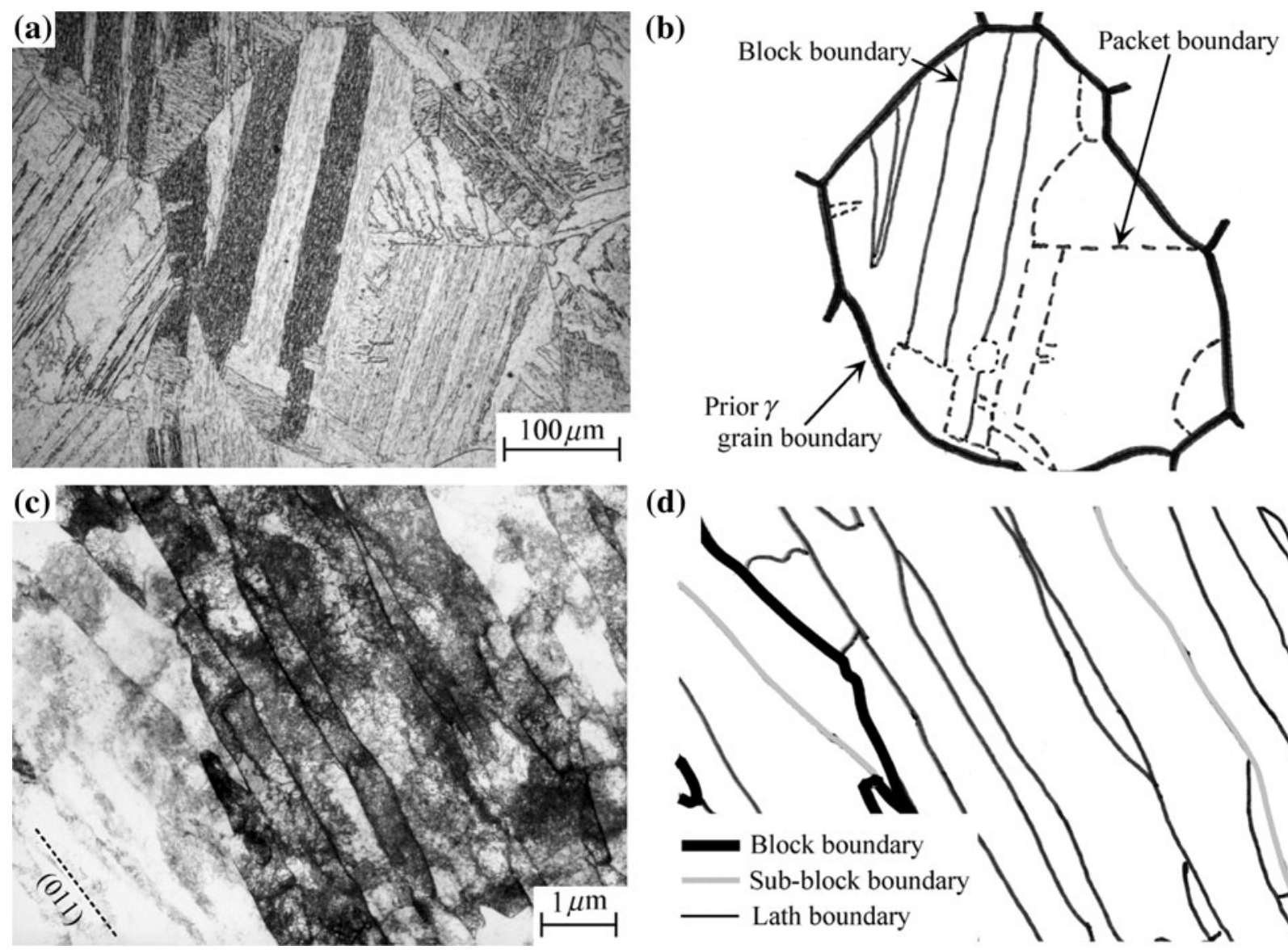

(d)

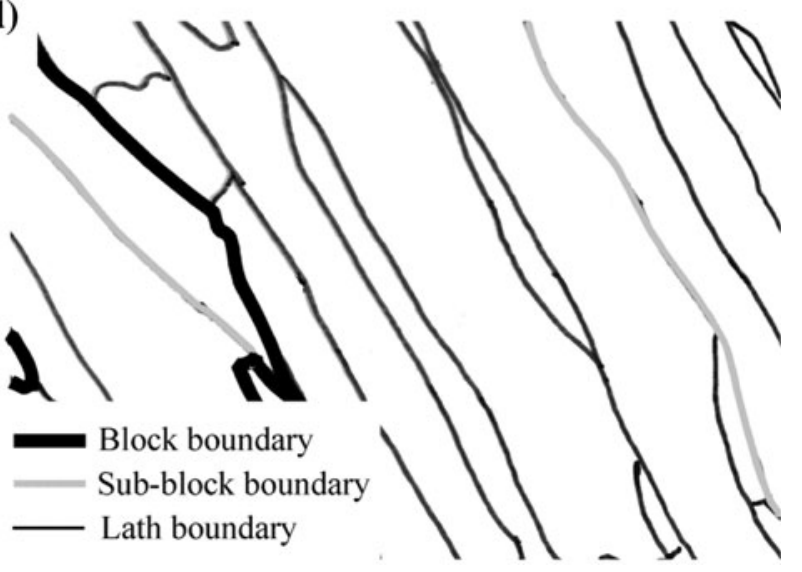

Fig. 1-The initial structure of lath martensite: $(a)$ optical micrograph etched with 3 pct nital, $(b)$ schematic illustration of (a), (c) TEM image of a packet, and (d) schematic illustration of (c).

Table I. Structural Parameters of Four Different Initial Structures

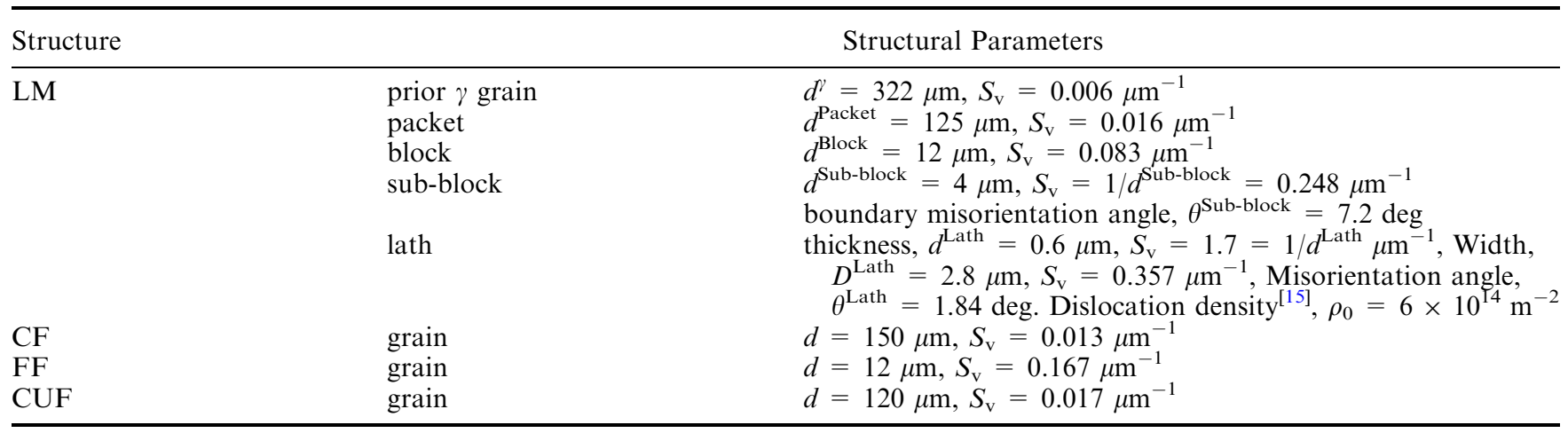

5 pct and 10 pct cold-rolled martensite are shown in Figure 3. Figure 3(a) shows the presence of sub-block boundaries at a peak of 7 to $8 \mathrm{deg}$ in undeformed LM. This peak vanishes as the rolling reduction is increased (Figures 3(b) and (c)). In parallel, the frequency of boundaries with lower angles increases. As the rolling reduction increases, the characteristic martensite structure gradually transforms into a rolling structure composed of extended boundaries with a high dislocation density and short interconnecting cell boundaries. ${ }^{[3]}$ This is illustrated in Figures 4 and 5 showing the structure after 30 pct and 50 pct reductions, respectively. The transition is followed by localized shear appearing as S-bands similar to those observed in deformed singlephase metals. ${ }^{[11]}$ However, when compared with CF and FF samples (see below), the microstructure in deformed LM is significantly finer, which is apparent from micrographs and is illustrated by the microstructural parameters given in Table II. Finally, when the rolling reduction is increased to $80 \mathrm{pct}$, a typical lamellar structure has evolved with extended boundaries almost parallel to the rolling plane (Figure 6).

The structural evolution with increasing strain is similar in $\mathrm{CF}$ and FF samples and is comparable with 


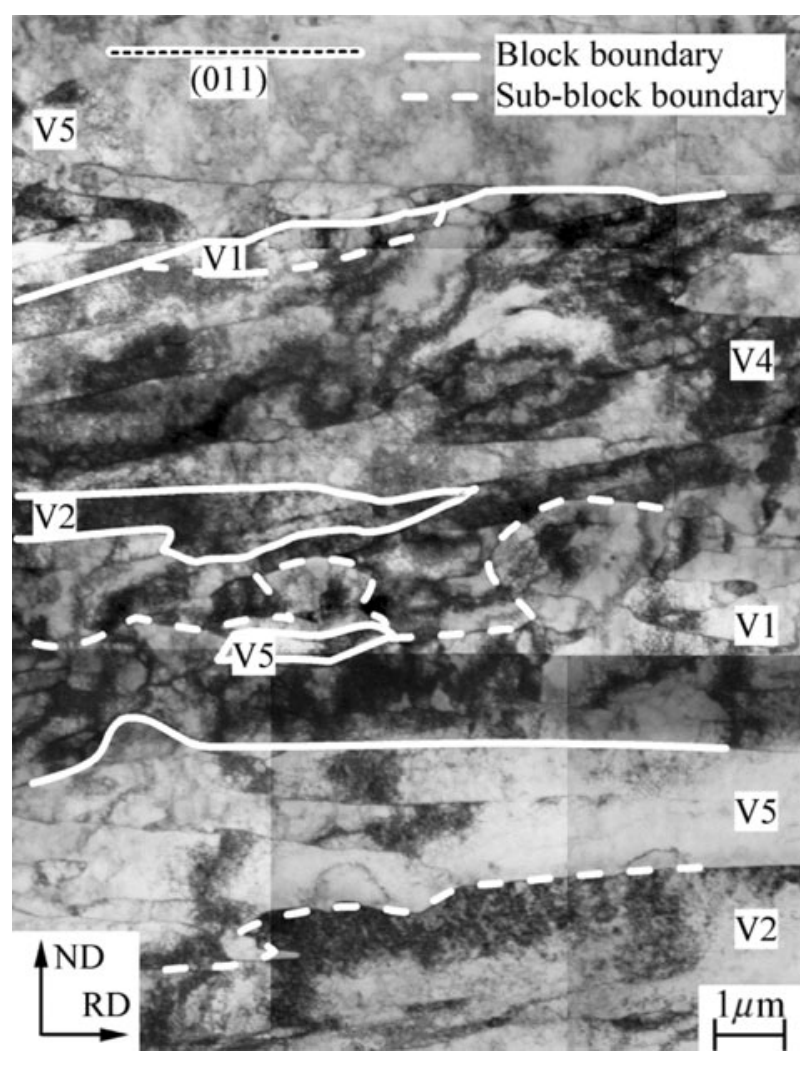

Fig. 2-TEM image of LM after 10 pct cold rolling observed from the TD. Note that the lath boundaries have started to vanish.

the evolution in a previous study of unalloyed IF steel with a grain size of $120 \mu \mathrm{m},{ }^{[12]}$ which has been cold rolled to reductions in the range $10 \mathrm{pct}$ to $90 \mathrm{pct}$ $\left(\varepsilon_{\mathrm{vM}}=0.12\right.$ to 2.65$)$. In this study, at low to medium strain, extended dislocation boundaries and short cell boundaries subdivide the structure with the extended boundaries forming an angle of approximately 40 deg to the rolling direction. As the strain increases, localized shearing in the form of S-bands is a typical feature in a structure that gradually transforms into a lamellar structure at large strain where the structure is subdivided by extended lamellar boundaries and short interconnecting boundaries. The structural evolution in the cold-rolled CF sample is illustrated in Figures 7 through 9 for reductions of $10 \mathrm{pct}, 50 \mathrm{pct}$, and $80 \mathrm{pct}$, respectively. The structural parameters are given in Table II as distances between extended and interconnecting boundaries, which in accordance with previous work ${ }^{[3]}$ are classified as geometrically necessary boundaries (GNBs) and incidental dislocation boundaries (IDBs), respectively. Table II shows that a decrease in the initial grain size leads to a structural refinement at large strain $(80 \mathrm{pct})$. The table also shows that the spacing between high-angle boundaries is significantly affected by the initial grain size being $4.1 \mu \mathrm{m}$ and $1.2 \mu \mathrm{m}$ in CF and FF, respectively, after a reduction of 80 pct. Note that the ratio between these numbers is 3.4 compared with 12.5 between the original grain sizes pointing to an enhanced formation of deformation induced high-angle boundaries when the grain size is large.
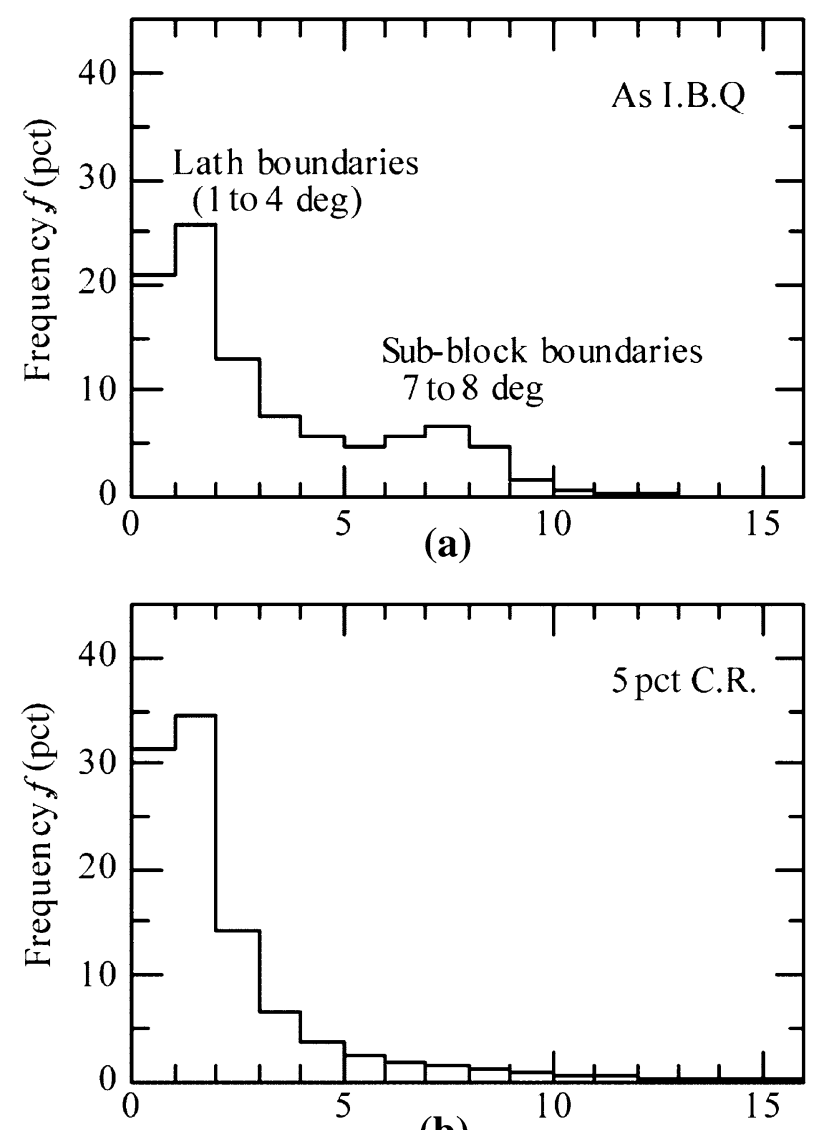

(b)

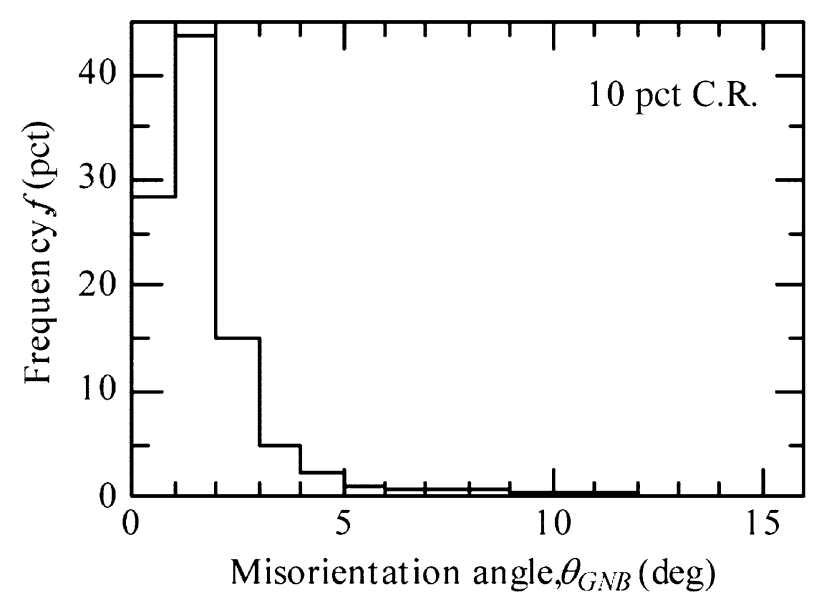

(c)

Fig. 3-Histograms showing the distributions of the misorientation angles across the lath and sub-block boundaries for $(a)$ undeformed martensite and $(b) 5$ pct and (c) 10 pct cold-rolled martensite.

A comparison of the results in $\mathrm{CF}$ samples with those in UCF samples ${ }^{[12]}$ suggests that the structural parameters are not significantly affected by the addition of $\mathrm{Mn}$ and $\mathrm{B}$. This similarity is reflected in the spacing between and misorientation angles across GNBs and IDBs given in Table II. Note in this table that the IDB spacing is smaller in the alloyed material indicating a higher dislocation density stored in IDBs. Furthermore, the dislocation density between IDBs is not negligible. The dislocation density of 80 pet cold-rolled CF was 


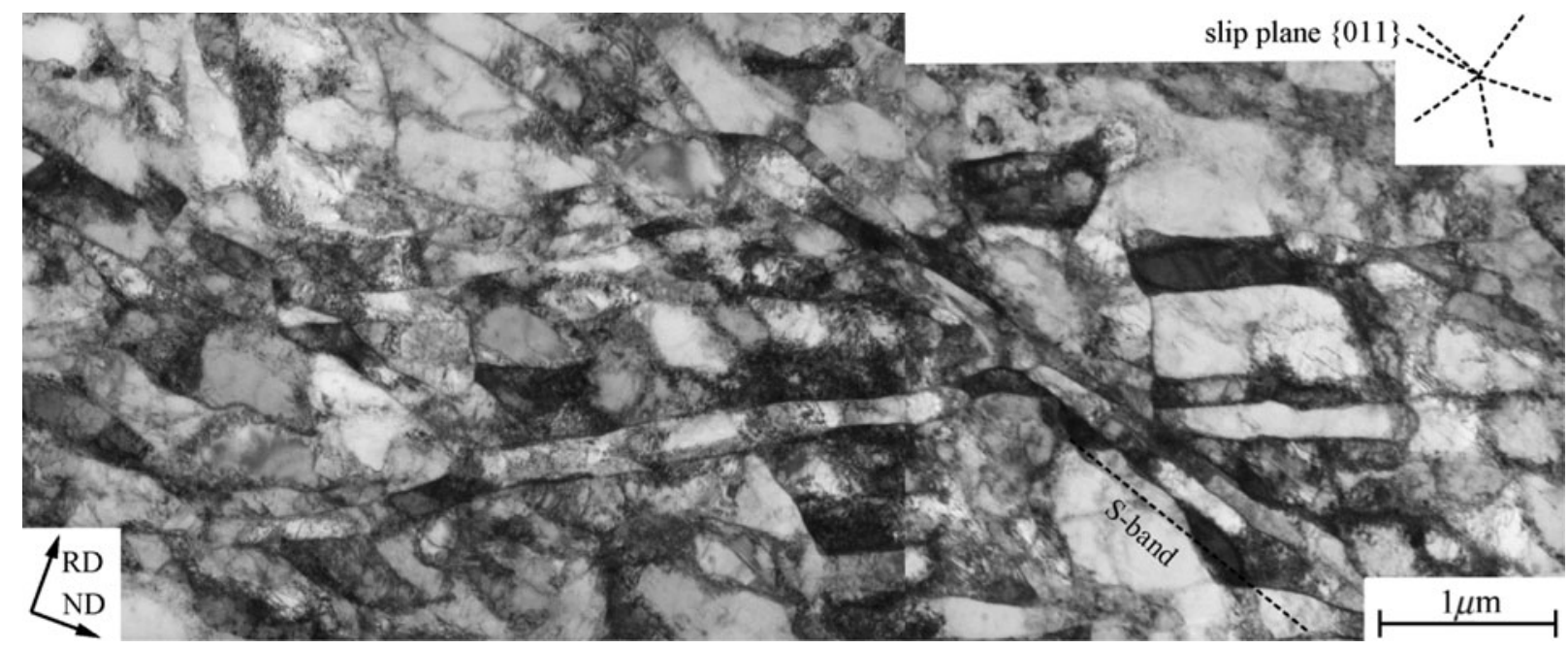

Fig. 4-TEM image of LM after 30 pct cold rolling observed from the TD. The traces of $\{110\}$ slip planes are calculated based on the measured local orientation and indicated by the dashed lines in the image.

found to be approximately $3 \times 10^{14} \mathrm{~m}^{-2}$ by TEM observations significantly higher than observed in coldrolled, unalloyed IF steel. ${ }^{[12]}$

The texture evolution in LM and CF is compared in Figure 10 after 80 pct rolling reduction. In both samples, the $\alpha$-fiber $(\mathrm{RD} / /\langle 110\rangle)$ and the $\gamma$-fiber $(\mathrm{ND} / /\{111\})$ have developed, however, with a lower intensity in LM than in CF. In Table III is the relationship between texture and microstructure that illustrates that both the $\alpha$-fiber and the $\gamma$-fiber components are represented in the lamellar structure. A small concentration of cube texture is also found, which is characterized by an equiaxed cell structure. This observed correspondence between texture and microstructure agrees with previous observations at low and medium strains that there is a correlation between the microstructure and the crystallographic orientation of the volume in which it develops. ${ }^{[20]}$

\section{Mechanical Properties}

The hardness as function of rolling reduction is shown in Figure 11. For CF and FF, a typical hardening behavior is observed with a decreasing hardening rate (stage III) up to a reduction of 30 pct followed by hardening at a constant rate (stage IV) to a reduction of 80 pet without saturation. For LM, the hardness is almost unaffected by the strain up to $30 \mathrm{pct}$ reduction, and at higher strain, linear hardening is observed with a rate almost similar to that of $\mathrm{CF}$ and FF. Note that LM has a much higher strength than CF and FF at low strain and that this difference is significantly reduced at medium to large strains.

The tensile properties of the four samples are given in Table IV, and the stress-strain curves are shown in Figure 12 for undeformed samples and after a rolling reduction of 80 pct. These tensile data show (1) that a yield phenomenon is not observed in any of the specimens, (2) that the uniform elongation in the undeformed sample is low in LM ( 2 pct) and high in $\mathrm{CF}$ and FF (20 to $30 \mathrm{pct}$ ), and (3) that the uniform elongation is low (1 to $2 \mathrm{pct}$ ) in all samples cold rolled to
80 pct reduction where the total elongation is high ( 8 to $10 \mathrm{pct}$ ) typically for highly strained materials. ${ }^{[21-26]}$ Table IV includes data from a recent study of $\mathrm{UCF}^{[12]}$ showing a significant solid solution strengthening but only at large strain (80 pct).

\section{STRUCTURAL PARAMETERS, STRENGTHENING MECHANISMS, AND FLOW STRESS}

The structural evolution points to two dominating strengthening mechanisms, grain boundary hardening and dislocation strengthening, which may be superimposed both in the undeformed lath martensite and in all the deformed samples. High-angle boundaries are present as grain boundaries in the initial structure and as deformation-induced high-angle boundaries in the deformed structure. Dislocations are stored in different types of low-angle boundaries and are present in the volumes between boundaries. The evolution in mechanical properties with increasing strain shows that at low and medium strain LM exhibits an almost constant hardness while ferrite structure shows stage III hardening. For all samples, stage II (linear) hardening is not observed at low and medium strain. These observations of structure and properties are the basis for the following discussion of strengthening mechanisms and strengthening parameters.

\section{A. Grain Boundary Hardening}

The glide resistance due to the presence of high-angle boundaries is related to the inverse square root of the boundary spacing expressed by the Hall-Petch equation for the yield stress and flow stress, respectively ${ }^{[8]}$ :

$$
\begin{gathered}
\sigma_{y}=\sigma_{0}+k_{1} D_{\mathrm{GB}}^{-1 / 2} \\
\sigma(\varepsilon)=\sigma_{0}(\varepsilon)+k(\varepsilon) D_{\mathrm{GB}}^{-1 / 2}
\end{gathered}
$$



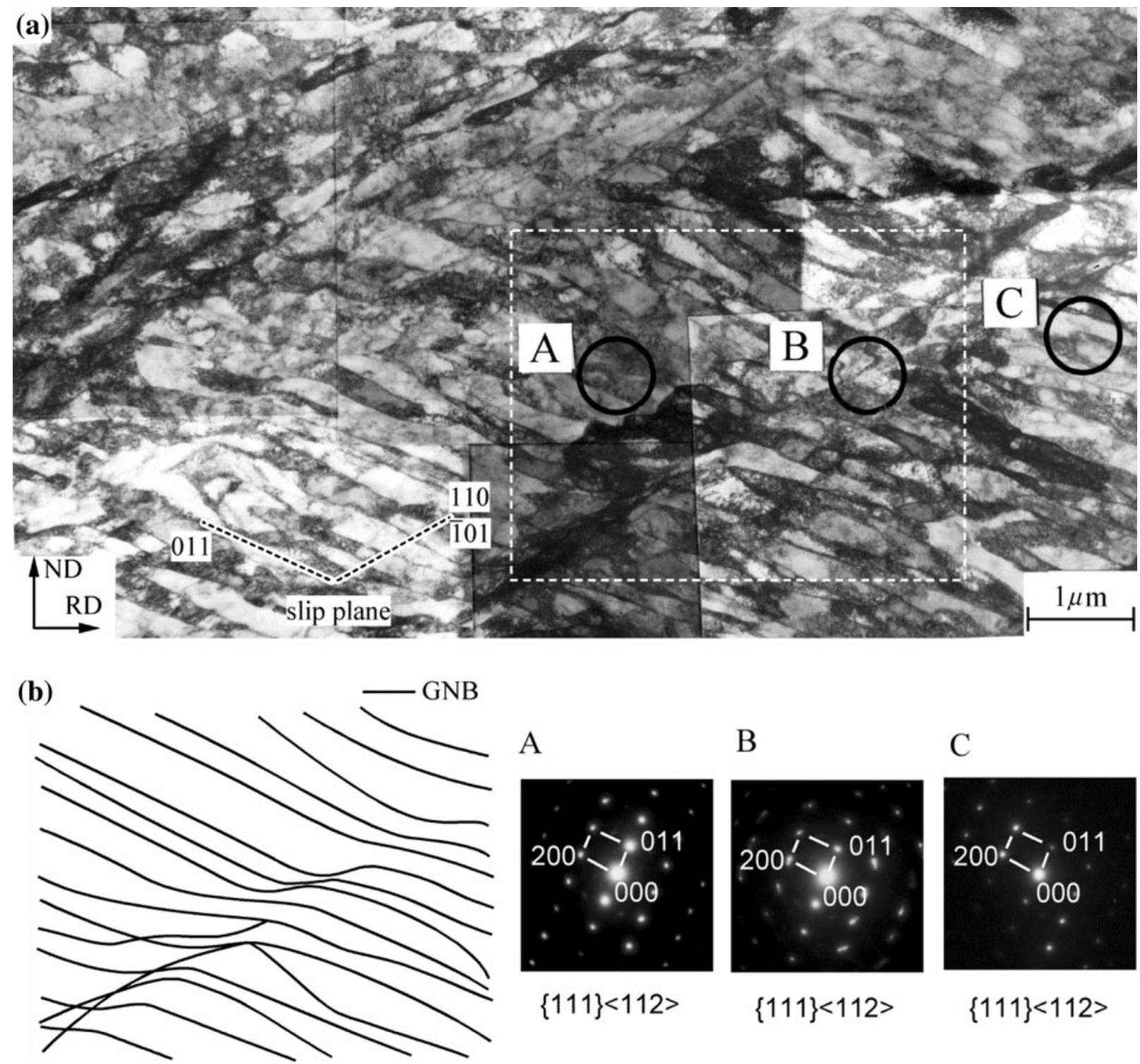

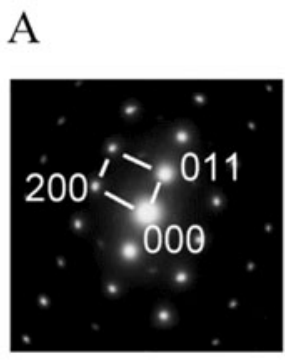

$\{111\}<112>$
B

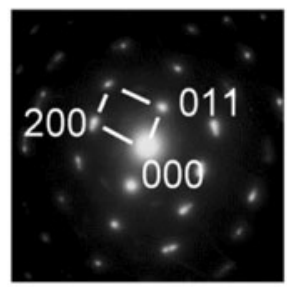

$\{111\}<112>$
$\mathrm{C}$

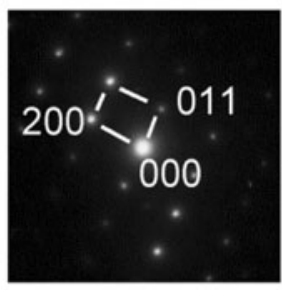

$\{111\}<112>$

Fig. 5- (a) TEM image observed from the TD showing the deformation microstructure after 50 pct cold rolling of LM. The traces of $\{110\}$ slip planes that are parallel to the boundary directions are marked. The orientation of the area is near ND/RD $=\left(\begin{array}{lll}1 & 1 & 1\end{array}\right) /\left[\begin{array}{lll}2 & -1 & -1\end{array}\right]$. The morphology of dislocation boundaries is elongated along the trace of the (011) slip plane in areas A and C, whose electron diffraction patterns are shown in $\mathrm{A}$ and $\mathrm{C}$. In area B, there is localized shear band, whose electron diffraction pattern is shown in B. $(b)$ A sketch showing the dislocation boundaries and localized shear band in the dashed frame indicated in (a).

where $\sigma_{0}, \sigma_{0}(\varepsilon), k_{1}$, and $k(\varepsilon)$ are constants. These constants may be affected by the presence of solutes and they have been determined by tensile testing of samples of the B- and Mn-containing IF steel with different grain sizes. For the yield stress ( 0.2 pct offset) and the flow stress (UTS), the following numbers have been obtained:

yield stress: $\sigma_{0}=111 \mathrm{MPa}, k_{1}=217 \mathrm{MPa} \mu \mathrm{m}^{1 / 2}$ flow stress: $\sigma_{0}(\varepsilon)=247 \mathrm{MPa}, k(\varepsilon)=373 \mathrm{MPa} \mu \mathrm{m}^{1 / 2}$

In comparison, the numbers for the yield stress $(0.2 \mathrm{pct}$ offset) of UCF steel ${ }^{[12]}$ are $\sigma_{0}=50 \mathrm{MPa}$ and $k_{1}=120 \mathrm{MPa} \mu \mathrm{m}^{1 / 2}$.

The grain size in Eqs. [1] and [2] for undeformed lath martensite $D_{\mathrm{GB}}$ is estimated as the average spacing between high-angle boundaries.

\section{B. Dislocation Strengthening}

Dislocations are present in low- and medium-angle boundaries $\left(\rho_{b}\right)$ and in the volumes between boundaries $\left(\rho_{0}\right)$. As the dislocation boundaries are of mixed tilt/ twist character, $\rho_{b}$ can for boundaries with a low angle $(\theta)$ be expressed by the relationship ${ }^{[1]}$

$$
\rho_{b}=1.5 S_{\mathrm{V}} \frac{\theta}{b}
$$

where $S_{\mathrm{V}}$ is the boundary area per unit volume and $b$ is the magnitude of the Burgers vector.

On the assumption that the dislocations are randomly distributed, their glide resistance can be expressed by the equation ${ }^{[11]}$ 
Table II. The Average Spacing and Misorientation Angle of Dislocation Boundaries and Dislocation Densities Between These Boundaries Resulting from Cold Rolling

\begin{tabular}{|c|c|c|c|c|c|c|c|}
\hline Specimen & $\begin{array}{l}\text { Reduction } \\
\text { (pct) }\end{array}$ & $\begin{array}{l}\text { Spacing of } \\
\text { HABs }(\mu \mathrm{m})\end{array}$ & $\begin{array}{c}\text { Spacing } \\
\text { of GNBs, } \\
d^{\mathrm{GNB}}(\mu \mathrm{m})\end{array}$ & $\begin{array}{c}\text { Misorienation } \\
\text { Angle of GNBs, } \\
\theta_{\mathrm{GNB}}(\mathrm{deg})\end{array}$ & $\begin{array}{l}\text { Spacing } \\
\text { of IDBs, } \\
d^{\mathrm{IDB}}(\mu \mathrm{m})\end{array}$ & $\begin{array}{c}\text { Misorienation } \\
\text { Angle of IDBs, } \\
\theta_{\mathrm{IDB}}(\mathrm{deg})\end{array}$ & $\begin{array}{c}\text { Dislocation } \\
\text { Density } \\
\rho_{0}\left(\mathrm{~m}^{-2}\right)\end{array}$ \\
\hline \multirow[t]{2}{*}{ LM } & 50 & 3.1 & 0.3 & $4.7^{*}$ & 0.5 & $1.4^{*}$ & + \\
\hline & 80 & 1.3 & 0.2 & 6.5 & 0.4 & 1.9 & $3 \times 10^{14}$ \\
\hline \multirow[t]{2}{*}{$\mathrm{CF}$} & 50 & 18.5 & 0.4 & $4.2^{*}$ & 0.8 & $0.7^{*}$ & $\ddagger$ \\
\hline & 80 & 4.1 & 0.3 & 5.4 & 0.5 & 1.2 & $3 \times 10^{14}$ \\
\hline $\mathrm{FF}$ & 80 & 1.2 & 0.2 & 6.3 & 0.5 & $1.2^{*}$ & + \\
\hline \multirow[t]{2}{*}{$\mathrm{UCF}^{[12]}$} & 50 & - & 0.4 & 3.8 & 0.9 & $1.7^{\dagger}$ & 末 \\
\hline & 80 & - & 0.3 & 5.3 & 0.8 & $1.9^{*}$ & $\ddagger$ \\
\hline
\end{tabular}

$$
\sigma(\varepsilon)=\sigma_{0}+\sigma_{\mathrm{ss}}+M \alpha G b \sqrt{\rho_{0}+\rho_{b}}
$$

where $\sigma_{0}$ is the friction stress, $\sigma_{\mathrm{ss}}$ is contribution from solid solution strengthening, $\alpha$ is a number $(0.24)$, and $G$ is the shear modulus ( $77 \mathrm{GPa}) . M$ is the Taylor factors that for the different samples are the following: $M=2.908$ for 80 pct cold-rolled LM, $M=3.020$ for 80 pct cold-rolled CF, and $M=2.860$ for 80 pet coldrolled FF.

The glide resistance of dislocation boundaries increases with their area density of dislocations, which is proportional to the misorientation angle for low-angle boundaries. However, it has been suggested that a certain critical angle exists above which the boundary will be impenetrable to glide dislocations and is considered as a grain boundary. This critical angle has been estimated to be of the order of 3 to 5 deg. ${ }^{[25]}$ This raises the question about the resistance of sub-block boundaries in lath martensite, which have a misorientation angles of 7 to $8 \mathrm{deg}$. However, these boundaries behavior differently from typical deformation-induced dislocation boundaries that at increasing strain reduce their spacing and increase their angles. The sub-block boundaries break down and distribute their dislocations when lath martensite is plastically deformed (Figure 3). The glide resistance of sub-block boundaries may therefore be lower than the resistance of high-angle boundaries present as block boundaries in lath martensite. This has led to an investigation ${ }^{[26]}$ where the glide resistance of sub-block and block boundaries has been investigated in an ultralow carbon Fe-23 mass pct $\mathrm{Ni}$ alloy, which has been austenitized and water quenched to obtain a lath martensite structure. By SEM, traces of slip bands have been characterized after bending of micron-size specimens that have been cut in such a way that a sample contains either a sub-block or a block boundary. The misorientation angle across a sub-block boundary is approximately $10.5 \mathrm{deg}$, and it has been found that this boundary resists glide insignificantly compared with a high-angle block boundary. This difference is reflected in the boundary strengthening that was estimated to be 28 and $136 \mathrm{MPa}$ for the subblock and block boundaries, respectively.

\section{Cell Block Strengthening}

The glide resistance in a cell block structure is expressed as the resistance of interconnecting boundaries (IDBs) superimposed on the resistance of the extended boundaries (GNBs) ${ }^{[11]}$ The IDBs are assumed to be penetrable to dislocations, whereas the GNBs are assumed to resist glide as do grain boundaries, and the flow stress has been expressed as ${ }^{[12]}$

$$
\sigma(\varepsilon)=\sigma_{0}+\sigma_{\mathrm{ss}}+M \alpha G b\left(1.5 \theta^{\mathrm{IDB}} S_{\mathrm{V}}^{\mathrm{IDB}} / b\right)^{1 / 2}+k /\left(2 d^{\mathrm{GNB}}\right)^{1 / 2}
$$

Equation [5] has been applied to calculate the flow stress of UCF samples rolled up to a reduction of 90 pct, and good agreement has been found between the calculated and the measured yield stress ( 0.2 pct offset) when using $k=120 \mathrm{MPa} \mu \mathrm{m}^{1 / 2}$ [12] $^{12}$

\section{Strength-Structure Relationships}

The microstructural characterization shows that welldefined structures are observed in undeformed lath martensite and in all samples deformed medium and large strains. This leads to an analysis of the following samples:

- LM-undeformed

- LM, CF, FF, UCF, and FF cold rolled to 50 and 80 pct

For these specimens, structural parameters are given in Table II and strength data in Table IV.

\section{E. Lath Martensite-Undeformed}

The strength of lath martensite is calculated as the sum of grain boundary and dislocation strengthening, and the parameters are the equivalent grain size and the total dislocation density. The equivalent grain size is $2 / S_{\mathrm{V}}$ where $S_{\mathrm{V}}$ is the boundary area per unit volume of prior austenite grain boundaries $\left(S_{\mathrm{V}}=0.006 \mu \mathrm{m}^{-1}\right)$, packet boundaries $\left(S_{\mathrm{V}}=0.016 \mu \mathrm{m}^{-1}\right)$, and block boundaries $\left(S_{\mathrm{V}}=0.083 \mu \mathrm{m}^{-1}\right)$ in total $0.105 \mu \mathrm{m}^{-1}$ corresponding to an equivalent grain size of $19 \mu \mathrm{m}$. 


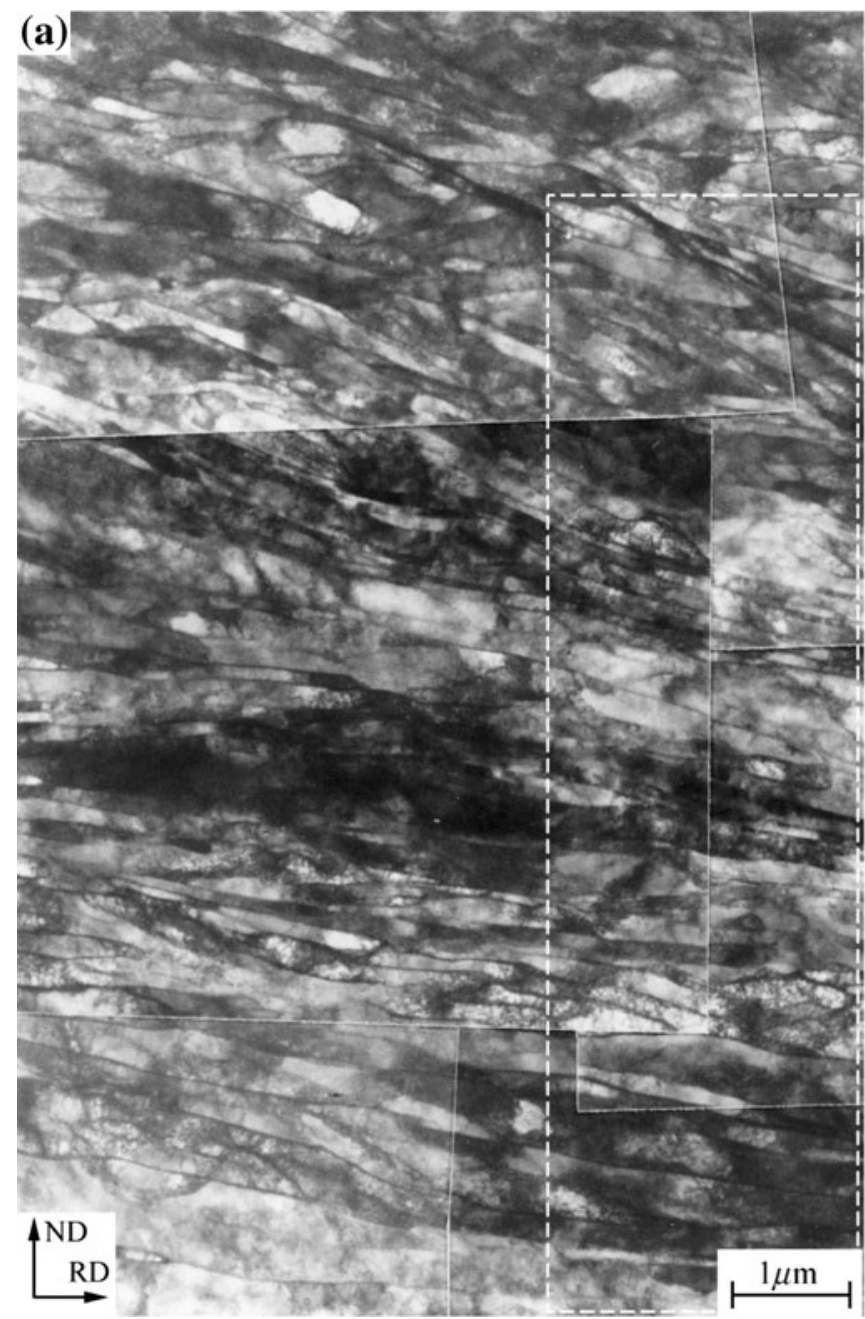

(b)

\section{- Lamellar boundaries \\ Texture boundaries}

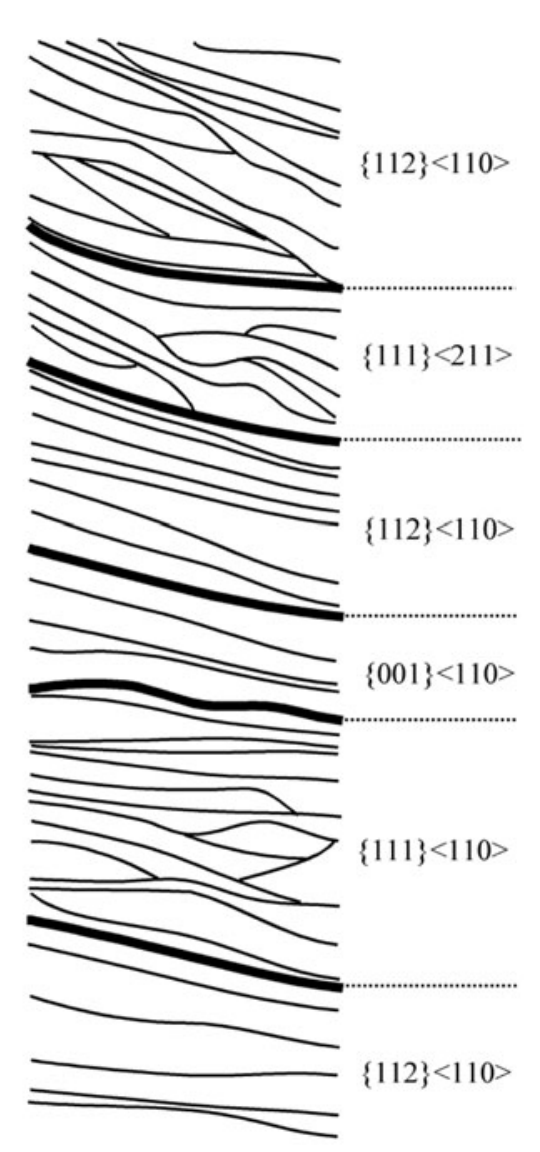

Fig. 6 - (a) TEM image observed from the TD showing the deformation microstructure after 80 pct cold rolling of LM. The microstructure is subdivided by lamellar boundaries nearly parallel to the rolling direction. (b) A sketch illustrates the subdivision into texture components in the area marked by white dashed lines in the micrograph.

Based on Eq. [1], the contribution due to grain boundaries is $\sigma_{\mathrm{GB}}=50 \mathrm{MPa}$. The total dislocation density in LM is the sum of contribution of sub-block boundaries (accounted for as dislocation boundaries; see Section IV-B) $\left(2 \times 10^{14} \mathrm{~m}^{-2}\right)$, lath boundaries $\left(3 \times 10^{14} \mathrm{~m}^{-2}\right)$, and dislocations between boundaries $\left(3 \times 10^{14} \mathrm{~m}^{-2}\right)$. The total dislocation density is approximately $8 \times 10^{14} \mathrm{~m}^{-2}$, and based on Eq. [5], the contribution due to dislocations is calculated using an average of experimentally measured $M$ values.

$$
\begin{aligned}
\sigma(\rho) & =3.0 \times 0.24 \times 10^{-9} \times 0.248 \times 77000 \sqrt{8 \times 10^{14}} \\
& =389 \mathrm{MPa}
\end{aligned}
$$

On the assumption of additive strengthening, the flow stress of LM is

$$
\begin{aligned}
\sigma & =\sigma_{0}+\sigma_{\mathrm{ss}}+\sigma(\mathrm{gb})+\sigma(\rho)=34+77+50+389 \\
& =550 \mathrm{MPa}
\end{aligned}
$$

which is in a good agreement with the flow stress $(0.2$ pct offset) $526.1 \mathrm{MPa}$ determined experimentally (Table IV).

\section{F. Cold-Rolled $L M, C F$, and FF}

The flow stress of the cold-rolled samples is calculated based on Eq. [5]. In this equation, $k$ is a measure of the resistance to glide by extended dislocation boundaries. For pure metals as $\mathrm{Al},{ }^{[27]} \mathrm{Ni}^{[11]}$ and $\mathrm{Fe}^{[12]}$ good agreement has been observed between the measured flow stress and the calculated one by using Eq. [5] and taken $K_{\mathrm{HP}}$ equal to the Hall-Petch constant the pure, polycrystalline material which for IF steel is $120 \mathrm{MPa} \mu \mathrm{m}^{1 / 2}{ }^{[12]}$ However, for the present samples containing solutes B and Mn, the Hall Petch slope was determined to be $217 \mathrm{MPa} \mu \mathrm{m},{ }^{1 / 2}$ showing that segregation of solutes to the grain boundaries have increased their resistance to glide. Some of these original grain boundaries are present in the deformed structure as GNBs and are accounted for together with deformation induced GNBs when measuring the spacing between GNBs. However, a comparison of this spacing with the distance between grain boundaries in the initial structure shows that the original grain boundaries only account for a relatively small fraction of the GNBs in the deformed samples. However, it is a question whether the 

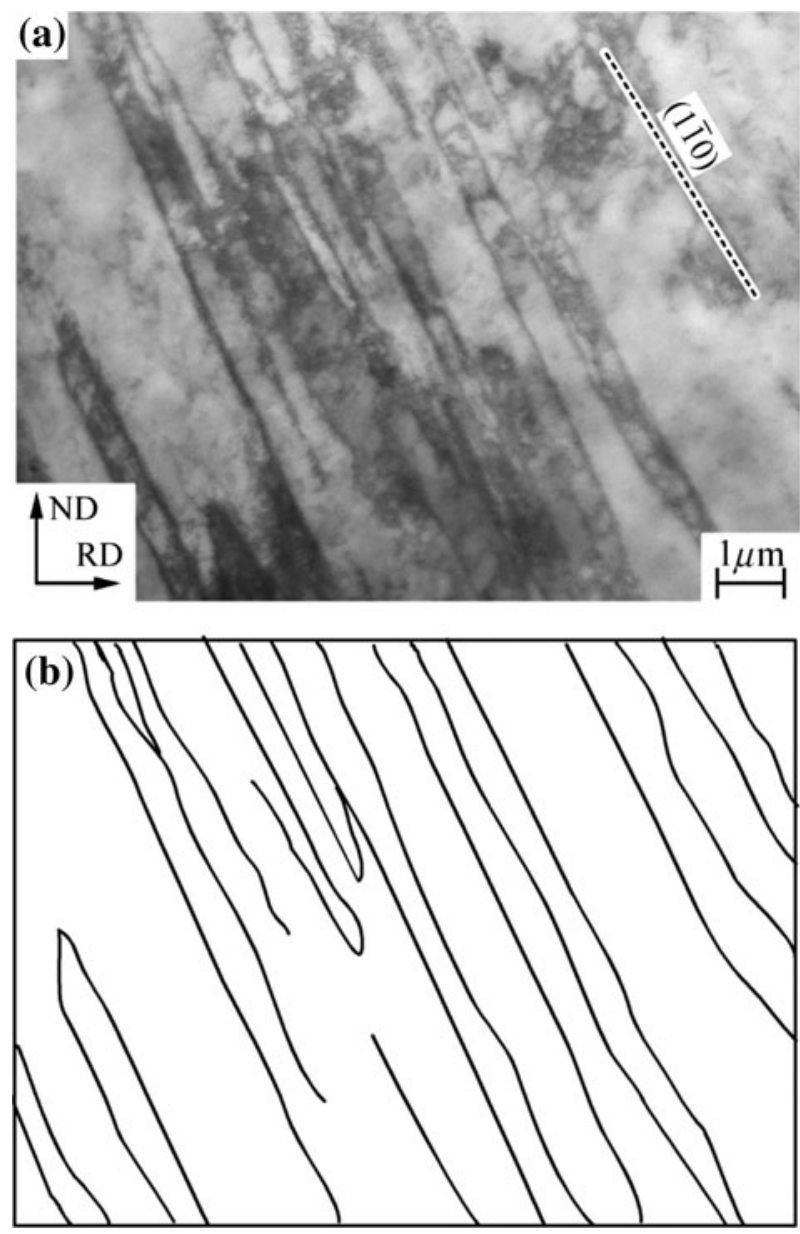

Fig. 7-(a) TEM image of CF $(d=150 \mu \mathrm{m})$ after 10 pct cold rolling observed from the TD. (b) A sketch of the extended dislocation boundaries. The orientation of the grain is $\mathrm{ND} / \mathrm{RD}=(0.8220 .544$ $0.171) /[0.400-0.7640 .505]$. Many extended boundaries are aligned at 40 deg with respect to the rolling direction and parallel to the trace of the (1-10) plane, which is one of the active slip planes.

elements in solid solution affect the resistance of deformation-induced GNBs, which is tested on the assumption that strength contribution from dislocations $(\sigma(\rho))$ present in IDBs and between boundaries can be calculated based on Eq. [4] and that $\left(\sigma_{0}+\sigma_{\mathrm{ss}}\right)=$ $111 \mathrm{MPa}$. If it is further assumed that strength contributions are additive, then $k$ in Eq. [5] can be calculated based on measurement of flow stress ( 0.2 pct offset) and of $D^{\mathrm{GNB}}$. The calculated values for $k$ are shown in Table V, which gives an average value of $104 \pm$ $3 \mathrm{MPa} \mu \mathrm{m}^{1 / 2}$, which indicates that the presence of solutes may only have a small effect on the glide resistance of GNBs in agreement with the assumption. In order to ensure consistency with the previous study, ${ }^{[12]} k=120 \mathrm{MPa} \mu \mathrm{m}^{1 / 2}$ is applied in the calculation of the flow stress of samples deformed 50 and 80 pct showing a typical high strain lamellar structure. Calculated and experimental data are shown in Table VI and good agreement is found. The difference between LM and FF is a large contribution from $\sigma(p)$ in LM, and a comparison between $\mathrm{CF}$ and $\mathrm{FF}$ shows a large contribution from $\sigma(\mathrm{GNB})$ in $\mathrm{FF}$, indicating a significant effect of the precursor structure.

\section{DISCUSSION}

\section{A. Microstructural Analysis}

A key structural feature is the cell block composed of extended boundaries (GNBs) and cell boundaries (IDBs), which characterize the deformation structure of deformed ferritic samples and of lath martensite when it is deformed at medium to high strain. The morphology of the cell blocks evolves at large strain into a lamellar structure, and the distance between and the misorientation angle across GNBs and IDBs increase with strain without saturation. This evolution follows the universal pattern of grain subdivision in bcc and fcc metals of medium to high stacking fault energy, which deform by dislocation glide ${ }^{[1]}$ A novel observation is the transformation of lath martensite to cell blocks, which will be analyzed in Section V-B.

The effect of the initial structure on structural refinement during plastic deformation is illustrated by the magnitude of the average boundary spacing $\left(d_{\mathrm{a}}\right)$ in the structure subdivided by GNBs and IDBs. This spacing equals $2 / S_{\mathrm{V}}^{\mathrm{t}}$, where $S_{\mathrm{V}}^{\mathrm{t}}$ is the total area per unit volume given by the relationship

$$
S_{\mathrm{V}}^{\mathrm{t}}=\frac{1}{D^{\mathrm{GNB}}}+\frac{\pi}{2 D^{\mathrm{IDB}}}
$$

For the four different initial structures, the average boundary spacing at 50 and 80 pet reductions is given in Table VII. The numbers show that an initial content of dislocations (LM), a fine grain size, and a content of solute elements refine the deformed structure. The numbers also show the effect of each feature, as follows:

(a) The effect of an initial dislocation density by a comparison of LM with FF both having a fine grain size and a content of solute elements.

(b) The effect of grain size by a comparison of $\mathrm{CF}$ and FF both with a content of solute elements.

(c) The effect of elements in solute solution by a comparison of $\mathrm{CF}$ and $\mathrm{UCF}$ both having a large grain size but with and without a content of solute elements.

The finest spacing is found in rolled martensite $0.22 \mu \mathrm{m}$ at a rolling reduction of $80 \mathrm{pct}$, showing a cumulative effect of the grain refinement caused by the three initial structures.

\section{B. Transformation of Lath Martensite}

The transition of lath martensite into a cell block structure can be underpinned by the observation of a number of similarities between the two features. For example, they both show a structure subdivided by dislocation boundaries and high-angle boundaries, and there is a clear resemblance between lath boundaries and cell boundaries. These dislocation boundaries have comparable small average misorientations and angular distributions, and both types of boundaries are of mixed tilt/twist character and show alternating misorientation across them. However, there are also differences for example that blocks, subblocks, and lath boundaries have specific crystallographic relationship between adjoining volumes, whereas cell 

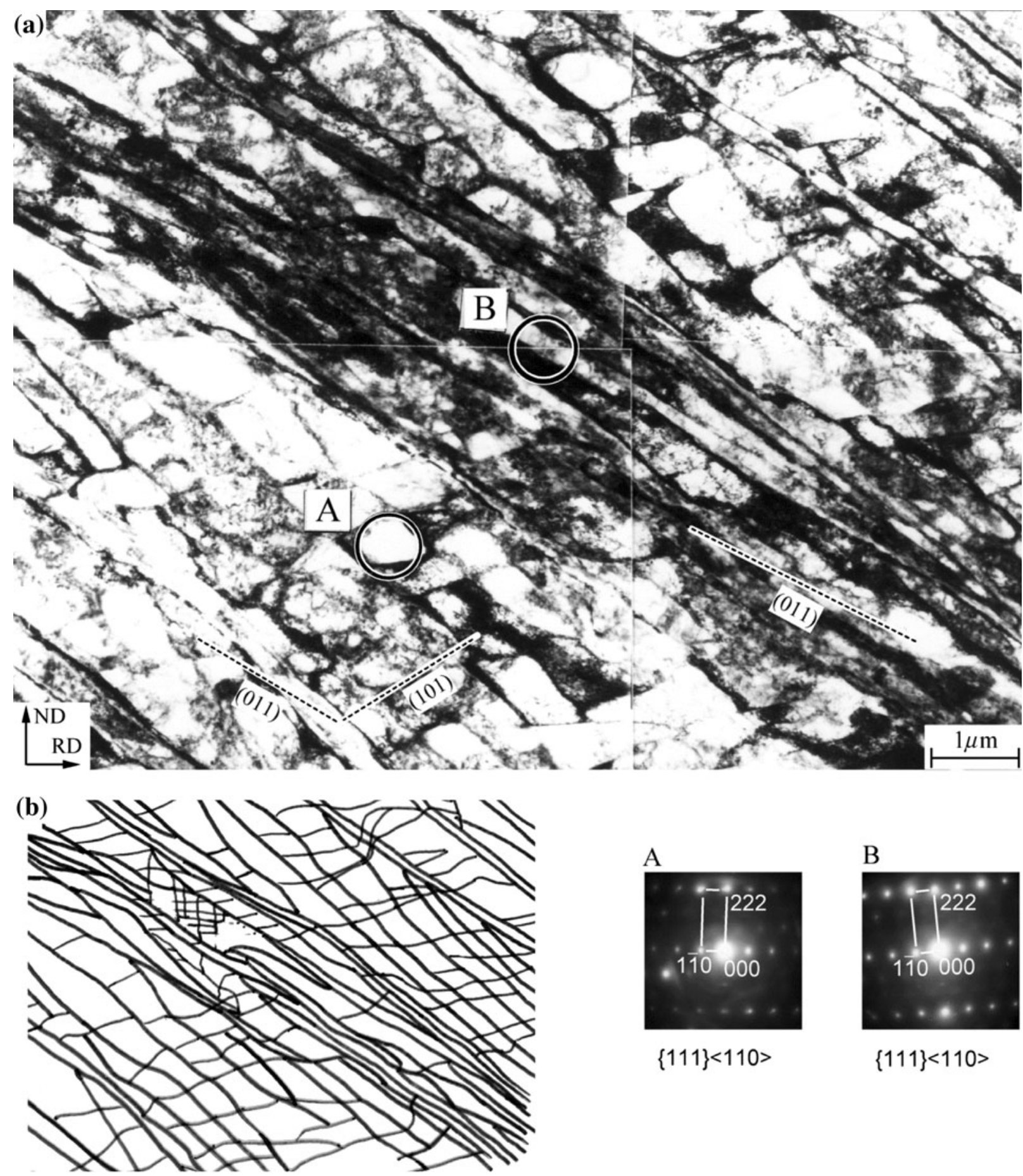

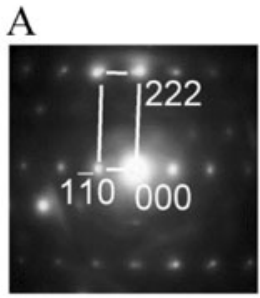

$\{111\}<110>$

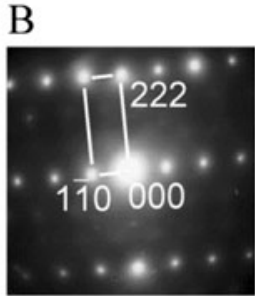

$\{111\}<110>$

Fig. 8- (a) TEM micrograph of CF after 50 pct cold rolling observed from the TD. (b) Sketch of the boundary structure. The orientation of the area is near ND/RD = (lll $\left.1 \begin{array}{lll}1 & 1\end{array}\right) /\left[\begin{array}{lll}1 & -1 & 0\end{array}\right]$. Two sets of extended dislocation boundaries in area A are observed that are parallel to (011) and (101) slip planes, respectively. In area B, microbands form on the (011) slip plane and the crystallographic orientation of area B is different from that of area A by a few degrees, as seen in the diffraction patterns.

blocks and cell boundaries do not show such relationships. Also, in the way dislocations are stored in the structure, there is a significant difference as the majority of dislocations in lath martensite are stored in very low angle lath boundaries whereas in a cell block structure a large fraction of the dislocations are stored in cell block boundaries of medium to high angle.
The different characteristics of lath martensite and cell block reflect the different mechanisms by which they are formed. For lath martensite, it is suggested ${ }^{[16,17]}$ that the structural break up has its origin in a minimization of the shape change during the phase transformation. For cell blocks, they are assumed to form as a result of reduction of the internal work during plastic 

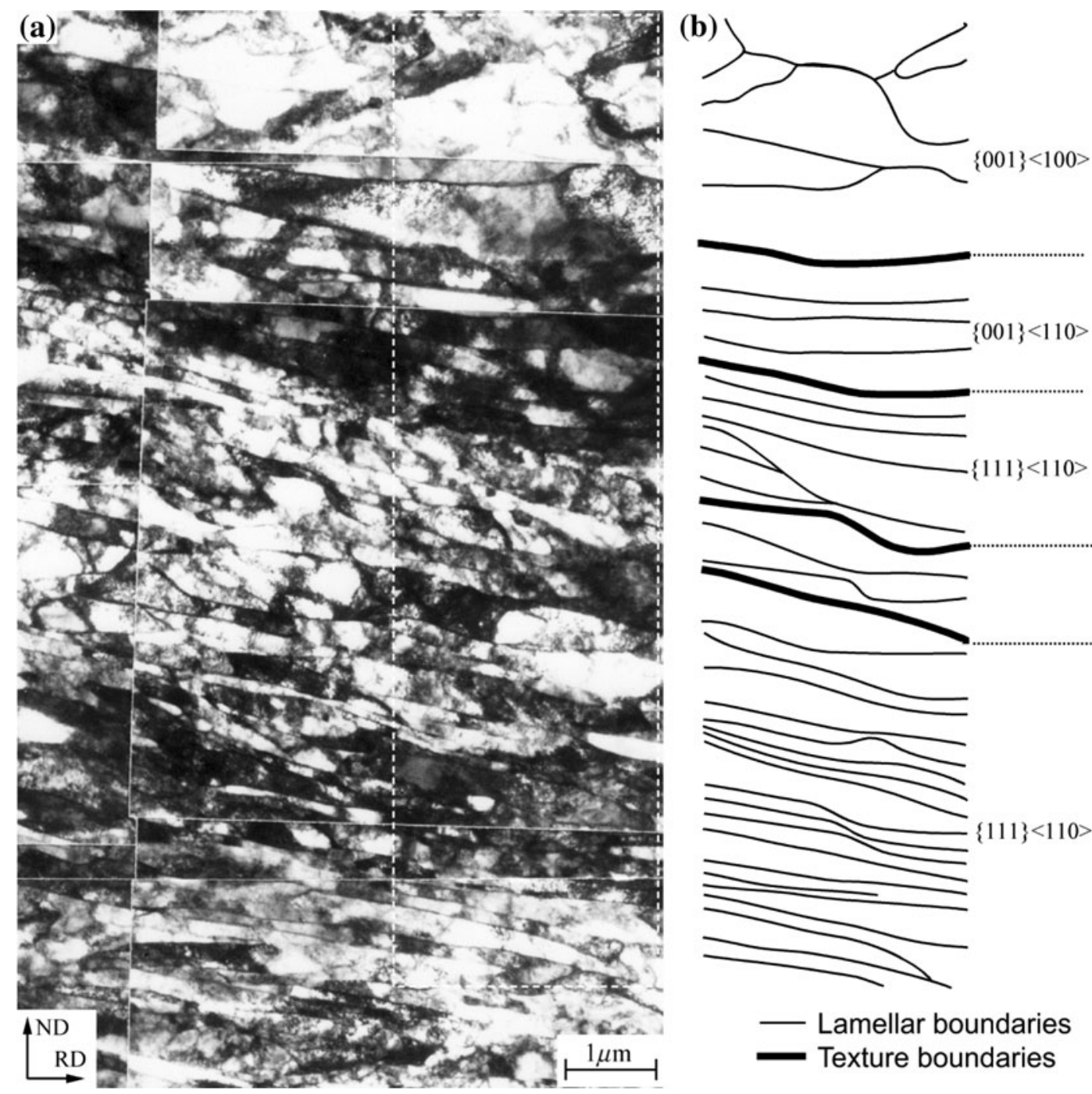

Fig. 9-(a) TEM image of CF after 80 pct cold rolling observed from the TD. (b) Sketch of the structure in the area marked by the dashed frame in (a). The identified texture components are shown in (b).

deformation by operation of fewer slip systems than required for homogenous deformation.

However, in both cases, the dominating mechanism is dislocation glide. It is concluded that both lath martensite and cell blocks are low-energy dislocation structures where the energy per unit line length $\left(u_{\mathrm{D}}^{*}\right)$ is minimized. However this energy may not be minimized to the same level in the two structures to be analyzed in the following.

In a stress-screened dislocation structure, $U_{\mathrm{D}}^{*}$ can to a first approximation be expressed by the equation ${ }^{[28]}$

$$
U_{\mathrm{D}}^{*}=\frac{G b^{2}}{4 \pi} f(\gamma) \ln \left(\frac{R}{b}\right)
$$

where $G$ is the shear modulus, $b$ is the Burgers vector, and $f(\gamma)=\left(1-\frac{\gamma}{2}\right) /(1-\gamma)$, where $\gamma$ is Poissons ratio. $R$ is the upper cut off radius that is reduced when dislocations assemble in boundaries instead of being randomly distributed. $R$ is also reduced when the misorientation angle $(\theta)$ of a low-angle boundary is increased as $R$ can be expressed by the relationship

$$
R=\frac{b}{\theta}
$$

Equations [7] and [8] together give

$$
U^{*}=A \ln \left(\frac{1}{\theta}\right)
$$

Where

$$
A=\frac{G b^{2}}{4 \pi} f(\gamma)
$$

$U^{*}$ increases with increasing dislocation density per unit area of boundary $\left(\rho_{b}\right)$, which is proportional to $(b / \theta)$ for small angles. Therefore, the organization of a given density of dislocations into a cell block structure replacing a lath structure will decrease $U_{\mathrm{D}}^{*}$ and create a driving force for the observed structural transition when the martensite is plastically deformed. Such a deformation may also affect the total dislocation density $(\rho)$ and 


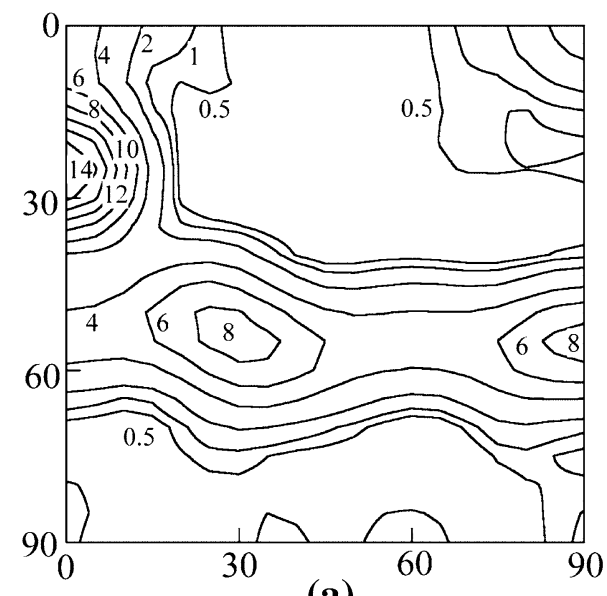

(a)

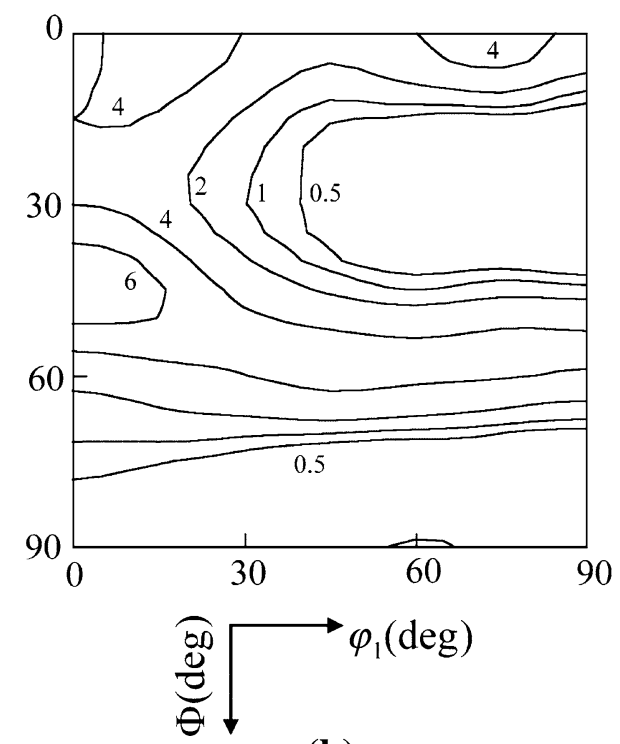

(b)

Fig. $10-\varphi_{2}=45$ deg sections of ODF for 80 pct cold-rolled (a) CF and (b) LM samples.

thereby the total stored energy expressed by the relationship

$$
U_{\mathrm{D}}=\rho U_{\mathrm{D}}^{*}
$$

The change in $\rho$ has not been determined in the current study, but it has been found ${ }^{[29]}$ by an X-ray and TEM investigation of lath martensite in an ultralow carbon $\mathrm{Fe}-18$ pct $\mathrm{Ni}$ alloy that a light prestraining $(0.15 \mathrm{pct})$ can reduce the density of mobile dislocations significantly from $7 \times 10^{15}$ to $4 \times 10^{15} \mathrm{~m}^{-2}$ thereby reducing $U_{\mathrm{D}}$. In parallel, it has been observed that randomly distributed dislocations start to organize into cell boundaries. It follows that the light prestrain leads to a decrease in both $U_{\mathrm{D}}^{*}$ and $U_{\mathrm{D}}$. In the current study where the applied rolling strain during the transition is up to 30 pct, a certain increase in $\rho$ and $U_{\mathrm{D}}$ cannot be excluded but an analysis is for further research as the microstructure in the transition region is complex; as an alternative, the change in $U_{\mathrm{D}}$ may be analyzed by differential scanning calorimetry.

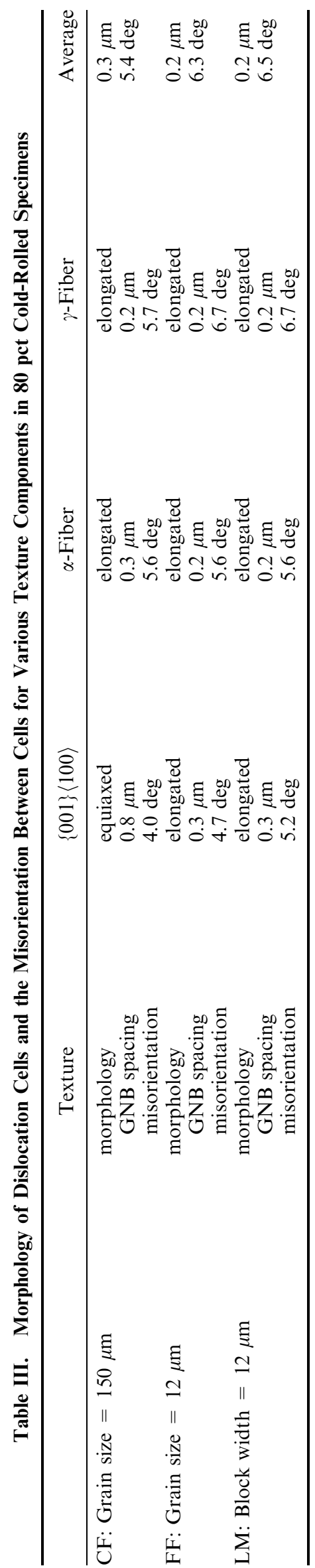




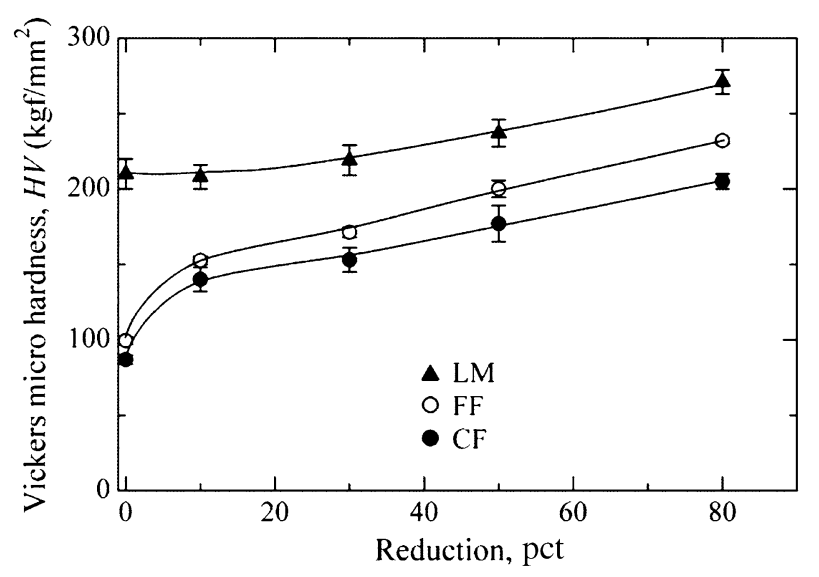

Fig. 11-Vickers microhardness of deformed specimens of IF steels. The solid circles, open circles, and solid triangles give the Vickers microhardnesses of $\mathrm{CF}, \mathrm{FF}$, and LM, respectively.

Table IV. Mechanical Properties of Samples with Different Initial Structures Before (0 pct) and After Cold Rolling to 80 pct Thickness Reduction

\begin{tabular}{lcccrr}
\hline Specimen & $\begin{array}{c}0.2 \mathrm{pct} \\
\text { Offset }(\mathrm{MPa})\end{array}$ & $\begin{array}{c}\mathrm{UTS} \\
(\mathrm{MPa})\end{array}$ & $\begin{array}{c}\text { Hardness } \\
\mathrm{HV}\end{array}$ & $\begin{array}{c}\left.\mathrm{UE} / \mathrm{km}^{2}\right) \\
(\mathrm{pct})\end{array}$ & $\begin{array}{c}\text { TE } \\
(\mathrm{pct})\end{array}$ \\
\hline LM0 & 526.1 & 562.4 & 210 & 1.8 & 14 \\
LM80 & 719.0 & 769.7 & 271 & 1.1 & 8 \\
CC0 & 131.2 & 277.6 & 87 & 24.3 & 43.6 \\
CF80 & 588.0 & 615.7 & 205 & 0.9 & 8.5 \\
FF0 & 178.8 & 355.0 & 108 & 21.9 & 46.1 \\
FF80 & 625.5 & 686.1 & 230 & 1.1 & 9.2 \\
UCF0 & 134 & 234 & - & 35.6 & 51.2 \\
UCF80 & 435 & 530 & - & 3.1 & 4.6 \\
\hline
\end{tabular}

TE: total elongation; UE: uniform elongation; UTS: ultimate tensile strength.

The general conclusion that a reduction in $U_{\mathrm{D}}^{*}$ creates a driving pressure for the structural transition is supported by the structural observation showing a significant reorganization of the dislocation structure and a breakdown of sub-block boundaries when LM is cold rolled. The fast reorganization of the structure illustrates a high mobility of dislocations to be expected in the ultralow carbon steel. As part of the reorganization, dislocations will interact also with dislocations of different Burgers vectors introduced during rolling. As a consequence, dislocation annihilation may take place and the stress screening of dislocation boundaries may be enhanced leading to a decrease in $U_{\mathrm{D}}^{*}$. This means that although both lath martensite and cell blocks are low energy dislocation structures, they represent different levels of $U_{\mathrm{D}}^{*}$.

As a general observation, it appears like the observed structural transition in martensite when glide systems activated by rolling are superimposed on systems activated during the phase transformation resembles the observation of a rearrangement of dislocation structures during plastic deformation involving strain path changes. ${ }^{[30,31]}$

\section{Microstructure and Stress-Strain Behavior}

The stress-strain behavior is illustrated in Figure 11 showing the hardness as a function of the rolling

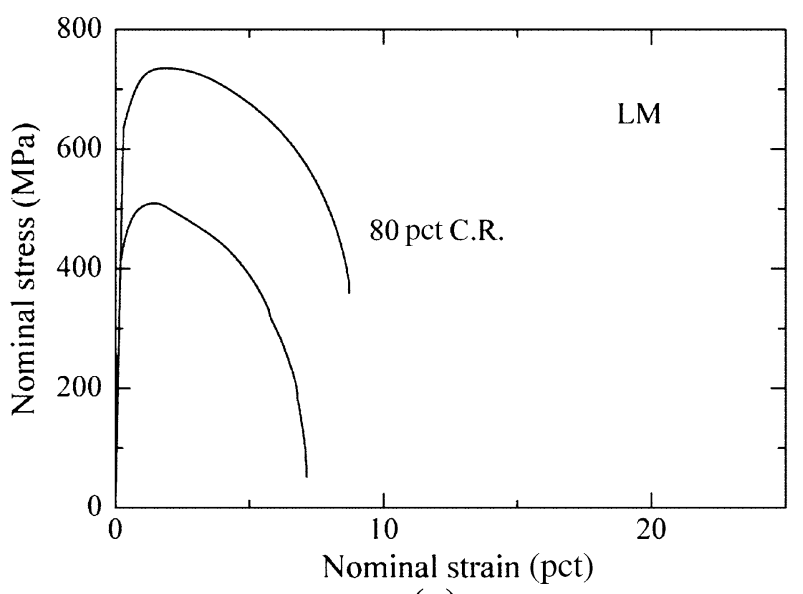

(a)

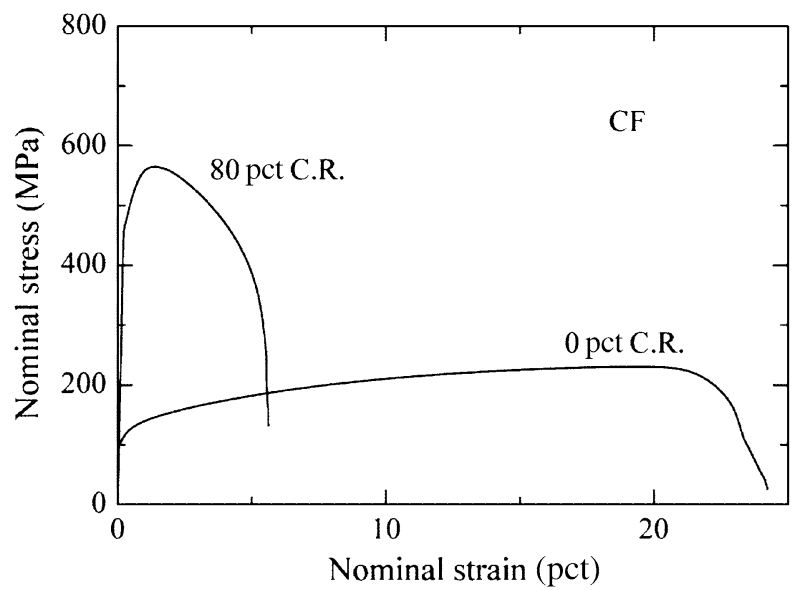

(b)

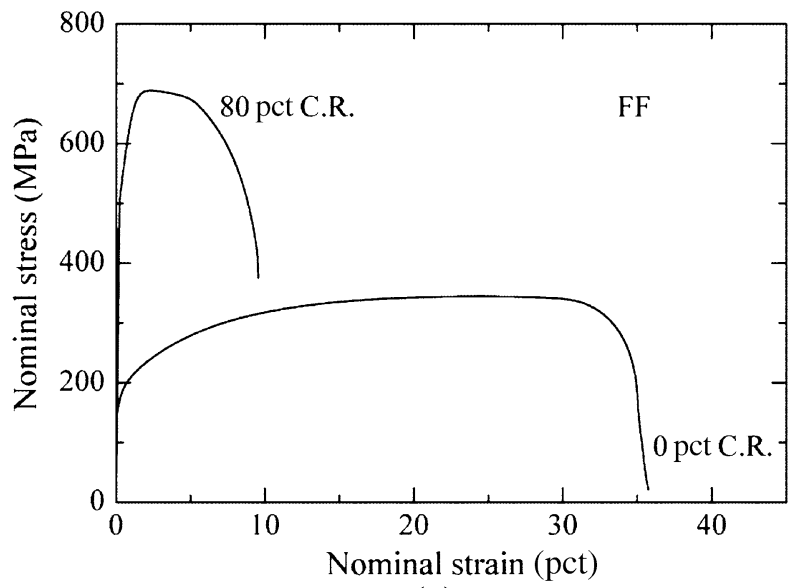

(c)

Fig. 12-The stress-strain curves of 0 and 80 pct cold-rolled specimens of IF steels: (a) LM, (b) CF, and (c) FF.

reduction. These curves illustrate a similar hardening behavior of the ferrite samples (CF and FF) also observed for $\mathrm{UCF}^{[12]}$ negligible hardening in $\mathrm{LM}$ at low-strain, and stage IV hardening in all specimens at medium to large strain. For UCF at all strains ${ }^{[12]}$ and for $\mathrm{LM}, \mathrm{CF}$, and FF at medium to large strain, good agreement has been found between calculated and observed values for the flow stress on the assumption 
Table V. Estimate of $k^{\mathrm{GNB}}(\mathrm{B}, \mathrm{Mn})$

\begin{tabular}{lccr}
\hline Sample & $\sigma(\mathrm{GNB})$ & $D^{\mathrm{GNB}}$ & $k($ est $)$ \\
\hline LM80 & 171.3 & 0.2 & 108.3 \\
CF80 & 127.9 & 0.3 & 99.1 \\
FF80 & 154.4 & 0.2 & 104.6 \\
\hline Ave $=104 \pm 2.7$ & & \\
$D_{\mathrm{r}}=2 D^{\mathrm{GNB}}$. & & \\
\hline
\end{tabular}

Table VI. Calculated and Experimentally Measured Yield Stress (0.2 pet Offset) for 80 pet Cold-Rolled LM, CF, and FF Samples

\begin{tabular}{lccccccc}
\hline Sample & $\sigma_{0}+\sigma_{\mathrm{ss}}$ & $\Delta \sigma(\rho)$ & $\sigma(\mathrm{GNB})$ & $\sigma(\mathrm{cal})^{\text {tot }}$ & $\sigma(\exp )$ & $\Delta$ & pct \\
\hline LM80 & 111 & 459 & 180 & 751 & 719 & 32 & 4.2 \\
CF80 & 111 & 371 & 151 & 633 & 588 & 45 & 7.2 \\
FF80 & 111 & 360 & 181 & 652 & 626 & 26 & 4.0 \\
\hline
\end{tabular}

of additive strengthening (Section IV), which has not been applied to LM at low strain where the complexity of the deformed microstructure makes it difficult to quantify the structural parameters. Qualitatively, however, the absence of work hardening may be related to the extensive reorganization of the dislocation structure, which may create a balance between dislocation annihilation and dislocation production in this strain range.

The effect of the initial structure on the flow stress in the deformed state follows the microstructural changes such that a decrease in the average boundary spacing corresponds to an increase in the stress in Figure 11. Note in this figure the strong effect of an initial dislocation density (compare LM and $\mathrm{CF}$ ) and the strong effect of elements in solute solution (compare $\mathrm{CF}$ and $\mathrm{UCF}^{[12]}$. These effects are cumulative, and a very high flow stress can be obtained in deformed LM (Table IV). Note also in Figure 11 the very high stress increase, which can be obtained at low to medium strain where LM is 100 pct and 50 pct higher than UCF and $\mathrm{CF}$, respectively.

\section{CONCLUSIONS}

For ultralow carbon IF steel containing $\mathrm{B}$ and $\mathrm{Mn}$ cold rolled up to a reduction of 80 pct $\left(\varepsilon_{\mathrm{vM}}=1.86\right)$, the evolution in microstructure, microstructural parameters, and flow stress has been characterized and analyzed for three initial structures: LM, FF, and CF. Results from a previous study ${ }^{[12]}$ on a cold-rolled UCF are also included for comparison. The following conclusions can be reached.

A key structural element is the cell block composed of cell block boundaries (GNBs) and cell boundaries (IDBs). For both types of boundaries, the boundary spacing decreases and the misorientation angle increases with increasing strain. An exception is lath martensite, where the cell blocks are generated through a transition from a lath martensite structure. The driving force for the transition is suggested to be a decrease in energy per
Table VII. Average Boundary Spacing $d_{\mathrm{a}}(\mu \mathrm{m})$

\begin{tabular}{llc}
\hline & 50 pct & 80 pct \\
\hline UCF & 0.47 & 0.38 \\
CF & 0.41 & 0.32 \\
FF & - & 0.25 \\
LM & 0.33 & 0.22 \\
\hline
\end{tabular}

unit length of dislocation line possibly supplemented by a reduction in stored energy.

The structural evolution at medium to large strain into a lamellar structure is enhanced when dislocations, grain boundaries, and solute elements are present in the initial structure. This enhancement is cumulative, leading to a decrease in the average boundary spacing in the order $\mathrm{UCF}, \mathrm{CF}, \mathrm{FF}$, to $\mathrm{LM}$, which has a spacing of approximately $0.2 \mu \mathrm{m}$. Saturation of the structural parameters has not been observed.

At small to medium strains, the hardening of lath martensite is negligible where the ferrite samples show stage III (parabolic) hardening. At medium to large strains, all samples show stage IV (linear) hardening.

On the assumption of additive strengthening from boundaries, dislocations, and solute elements, flow stress predictions are in good agreement with experimental values. The increase in the strength follows the decrease in the average boundary spacing, and the highest flow stress is $738 \mathrm{MPa}$ in LM deformed to 80 pct reduction. Saturation of the calculated and measured flow stress has not been observed.

The possibility of combining in a martensitic structure a high density of dislocations and grain boundaries together with elements in solute solution has potential in the current development of nanometals with high strength produced by plastic deformation where a requirement of an ultrahigh strain may be relaxed significantly.

\section{ACKNOWLEDGMENTS}

The authors acknowledge the Danish National Research Foundation for supporting the Danish-Chinese Center for Nanometals, within which part of the present work was performed. S.M. thanks the Center for Integrated Research in Science, Shimane University, for the permission to use the TEM.

\section{REFERENCES}

1. N. Hansen: Metall. Mater. Trans. A, 2001, vol. 32A, pp. 2917-35.

2. R. Ueji, N. Tsuji, Y. Minamino, and Y. Koizumi: Acta Mater., 2002, vol. 50, pp. 4177-89.

3. R. Ueji, N. Tsuji, Y. Minamino, and Y. Koizumi: Sci. Tech. Adv. Mater., 2004, vol. 5, pp. 153-62.

4. S. Morito, S. Iwamoto, and T. Maki: Proc. 1st Joint Int. Conf. of Rex\&GG, G. Gottstein, and D.A. Molodov, eds., Springer-Verlag, Aachen, Germany, 2001, pp. 1191-96.

5. S. Morito, X. Huang, T. Furuhara, T. Maki, and N. Hansen: Proc. 25th Riso Int. Symp. on Materials Science: Evolution of Deformation Microstructures in 3D, C. Gundlach, K. Haldrup, N Hansen, 
X. Huang, D.J. Jensen, T. Leffers, Z.J. Li, S.F. Nielsen, W. Pantleon, J.A. Wert, and G. Winther, eds., Risø, Denmark, 2004, pp. 453-58.

6. N. Hansen: Acta Metall., 1977, vol. 25, pp. 863-69.

7. A. van den Beukel: Scripta Metall., 1978, vol. 12, pp. 809-13.

8. N. Hansen: Yield, Flow and Fracture of Polycrystals, T.N. Baker, ed., Applied Science, London, U.K., 1983, pp. 311-48.

9. M.F. Ashby: Philos. Mag., 1970, vol. 21, pp. 399-424.

10. H.S. Chen, A. Godfrey, N. Hansen, J.X. Xie, and Q. Liu: Mater. Sci. Eng. A, 2007, vols. 483-84, pp. 157-60.

11. D.A. Hughes and N. Hansen: Acta Mater., 2000, vol. 48, pp. 2985-3004.

12. B.L. Li, A. Godfrey, Q.C. Meng, Q. Liu, and N. Hansen: Acta Mater., 2004, vol. 52, pp. 1069-81.

13. S. Zaefferer: J. Appl. Cryst., 2000, vol. 33, pp. 10-25.

14. Q. Liu: Ultramicroscopy, 1995, vol. 60, pp. 81-89.

15. S. Morito, J. Nishikawa, and T. Maki: ISIJ Int., 2003, vol. 43, pp. 1475-77.

16. S. Morito, H. Tanaka, R. Konishi, T. Furuhara, and T. Maki: Acta Mater., 2003, vol. 51, pp. 1789-99.

17. S. Morito, X. Huang, T. Furuhara, T. Maki, and N. Hansen: Acta Mater., 2006, vol. 54, pp. 5323-31.

18. C.A. Apple, R.N. Caron, and G. Krauss: Metall. Trans., 1974, vol. 5, pp. 593-99.
19. P.M. Kelly, A. Jostsons, and R.G. Blake: Acta Metall. Mater., 1990, vol. 38, pp. 1075-81.

20. X. Huang and G. Winther: Phil. Mag. A, 2007, vol. 87, pp. 5189-5214.

21. X. Huang, N. Hansen, and N. Tsuji: Science, 2006, vol. 312, pp. 249-51.

22. N. Tsuji, Y. Ito, Y. Saito, and Y. Minamino: Scripta Mater., 2002, vol. 47, pp. 893-99.

23. Y.T. Zhu and X.Z. Liao: Nature Mater., 2004, vol. 3, pp. 351-52.

24. M.A. Meyers, A. Mishra, and D.J. Benson: Progr. Mater. Sci., 2006, vol. 51, pp. 427-556.

25. N. Kamikawa, X. Huang, N. Tsuji, and N. Hansen: Acta Mater., 2009, vol. 57, pp. 4198-4208.

26. A. Shibata, T. Nagoshi, M. Sone, S. Morito, and Y. Higo: Mater. Sci. Eng. A, 2010, vol. 527, pp. 7538-44.

27. Q. Liu, X. Huang, D.J. Lloyd, and N. Hansen: Acta Mater., 2002, vol. 50, pp. 3789-3802.

28. N. Hansen and D.A. Hughes: Phys. Stat. Sol. B, 1995, vol. 149, pp. 155-72.

29. K. Nakashima, Y. Fujimura, H. Matsubayashi, T. Tsuchiyama, and S. Takaki: Tetsu-to-Hagané, 2007, vol. 93, pp. 459-65.

30. E.F. Rauch and J.H. Schmitt: Mater. Sci. Eng. A, 1989, vol. 113, pp. $441-48$.

31. J.H. Schmitt, J.V. Fernandes, J.J. Gracio, and M.F. Vieira: Mater. Sci. Eng. A, 1991, vol. 114, pp. 143-54. 